\title{
The Learning Organisation: Validating A Measuring Instrument
}

W.A. de Villiers, University of Pretoria, South Africa

\begin{abstract}
The EFMD reports in their Survey Summary Service (2006) that the topic of "The Learning Organisation" ranked in that year as the second most enduring idea about strategy and business, out of ten ideas most likely to last at least another ten years. Management literature contains a considerable number of references to the learning organisation and its characteristics. An instrument developed by Pedler, et al. (1991) to measure eleven characteristics of the learning organisation was used in the present study to measure the degree to which respondents considered their own organizations to conform to the eleven characteristics ascribed to the learning organisation. The aim of this paper is to report on the research and analyses being undertaken to better understand the factor structure and content of the construct, as well as the predictive and discriminatory validity of the same instrument. Item Analysis, Exploratory Factor Analysis and Confirmatory Factor Analysis were used for this purpose. The predictive/discriminatory validity of the instrument, which has been proved to be uni-dimensional, was investigated by means of One-way Analysis of Variance, Stepwise Discrimination Analysis and Discrimination Analysis. The results indicate that the instrument can adequately distinguish between respondents from different economic sectors and organisations as well as differentiate respondents in terms of some other variables. The study should be regarded as entirely applicable to the South African cultural and organizational environments.
\end{abstract}

\section{INTRODUCTION}

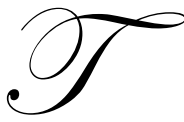

he phenomenon known as the learning organisations has during the past three decades been discussed widely in the literature (Khadra \& Rawabdeh, 2006; Moilanen, 2001, 2005; Hawkins, 1991; Watkins \& Marsick, 1993; Senge, 1990; Pedler, Burgoyne \& Boydell, 1991). It seems as if it could be argued that during the 1970s and 1980s strategy and organisational efficiency were emphasized instead. Hawkins (in Burgoyne, Pedler \& Boydell, 1994) emphasized the need for the soul of an organization to be activated and integrated with its operational and strategic functioning. This ties in with the views of Pedler, et al. (1991) who felt that the dream of the learning organisation is for people who believe that there is a massive locked-up, hidden, underdeveloped potential in organisations and who want to unlock, release and develop this potential. Davis (in Burgoyne, et al., 1994:57) appears to agree with this when he concludes: "We may need to find organisational forms in which the structure can embody the spirit and the spirit internalize the structure and in which both continually change". Reasons why learning organizations are needed are often adduced in the literature. The need for organisations to learn and develop, in order not to die, seems to be a popular concept (Khadra \& Rawabdeh, 2006; Armstrong \& Foley, 2003; Robinson, 1994; Senge, 1990; Skerlavaj \& Dimövski, 2006). Continuous improvement of one's product/service is vital in today's marketplace: organisations need to learn faster and smarter just to stay in the same place (DiBella \& Nevis, 1998). As the saying goes: "If you think learning is expensive, try ignorance".

Organisations are increasingly required to be learning systems (Nevis, et al., 1995) if they wish to survive and thrive in the current global dynamic business arena. The rate at which organizations learn and react, has emerged as a pre-eminent sustainable source of competitive advantage (Jashapara, 2003; Skerlavaj \& Dimövski, 2006). The learning organization concept is seen as a resource-based approach that is based on the ability of the organization to transform available resources into competences which are unique and cannot easily be copied by 
competitors (Karash (2002) in Khadra \& Rawabdeh, 2006; Liu, 2006; Michalisin, et al., 2006). Jamali, et al. (2006) concluded that a gradual evolutionary process is necessary for the learning organization to successfully integrate the characteristics of post-bureaucratic organizations - empowerment, teamwork, trust, open communication, commitment and flexibility . Coupled with a systems perspective this can explain how the learning organization disciplines may actually materialize.

A number of measurement instruments for assessing an organisation's current status in relation to the learning organization concept, have been developed (Moilanen, 2001). Yang, et al. (2004) developed and validated a multidimensional measurement tool of the learning organization based on its inception and practices. The instrument was recommended for use in organizational assessment projects. Pedler, et al. (1991) developed an instrument to measure what they termed: "the eleven characteristics of a learning company". This instrument is used to determine where the organisation is currently located on the way to becoming a fully fledged learning organisation. Too little is known about what is being measured by this questionnaire, however. The present study is therefore an attempt to determine the underlying dimensions measured by this instrument and to learn more about the portability or not, of the construct embodied in the instrument. In this way it was hoped to contribute towards a better understanding of what the whole notion of the learning organisation entails.

Research into the factor structure and content of the learning organisation construct was carried out. Results have shown that the construct as measured by Pedler, Burgoyne \& Boydell's (1991) eleven characteristics questionnaire seems to be uni-dimensional. Subsequently the predictive/discriminatory validity of the instrument, which has been proved to be uni-dimensional, was investigated by means of One-way Analysis of Variance. The results indicate that the instrument can adequately distinguish between respondents from different economic sectors and organisations as well as differentiate respondents in terms of some other variables.

\section{THEORETICAL BACKGROUND}

The learning organisation is to accelerates individual learning capacity, redefines organisational structure, culture, job design, mental models and encourage employee involvement. They promote a learning culture, a community of learners and ensure shared learning. Learning organisations seem to have cohesive structures of relationships among their members and the levels of learning in the organisation. Communication and participation seems to be key aspects (Agarwal (2005) in Khadra \& Rawabdeh, 2006; Skerlavaj \& Dimövski, 2006; Lim, et al., 2006; Kantabutra, 2006; Heath \& Brown, 2007).

Pedler, et al. (1991:1) described a learning organisation as “.... an organisation that facilitates the learning of all its members and continuously transforms itself". Watkins \& Marsick (1993) elaborate on the concept when they describe the learning organisation as one that learns continuously and transforms itself. Learning takes place in individuals, teams, the organisation, and even the communities with which the organisation interacts (Mayo, 2007; Watkins \& marsick,1996, 2003). Learning is a continuous, strategically used process integrated with, and running parallel to, work (Kenny, 2006). Learning results in changes in knowledge, beliefs and behaviors (Mayo,2007; Khadra \& Rawabdeh, 2006). The new culture should encourage employees' learning and involvement. It should be developed and sustained collectively to maximize employees' contribution to the organisation's goal of achieving excellence in performance through organizational. Learning also enhances organisational capacity for innovation and growth. The learning organisation has embedded systems to capture and share learning renewal (Skerlavaj \& Dimövski, 2006; Lim, et al., 2006; Michalisin, et al., 2006; Kantabutra, 2006). So many conceptions of the learning organisation have been advanced by different authors, which include several foci (Watkins \& Golembiewski, 1995) that consensus on the contents of the concept does not seem to exist, although there is much common ground amongst researchers (Yeo, 2003). From a scientific as well as a practical viewpoint, it seems to be necessary to clarify the concept as soon as possible in order to use the construct consistently and with confidence. For this to occur, reliable and valid measurement of the construct must be possible. Watkins and Marsick $(1996,2003)$ have developed the Dimensions of the Learning Organisation Questionnaire (DLOQ), to assess the extent to which an organization meets certain criteria as a learning organization. It had been validated by Yang (2003) as a research tool. 
Revans (1982) formulated the notion that for an organisation to survive, its rate of learning must be equal to, or greater than, the rate of change in its external environment. The term learning organization was first coined by Garratt in 1987 to describe organizations that experimented with new ways of conducting business in order to survive in turbulent highly competitive markets

(Örtenblad (2004) in Khadra \& Rawabdeh, 2006). To achieve this, the concept of the learning organisation and the importance of this type of approach was emphasized by Senge (1990). Some of the key influences making it necessary to move towards the learning organisation have been identified as: The need to achieve high and uniform levels of quality; rapid and continuous changes in technology; the need for a service orientation; global turmoil and competition; the world becoming a global village; the entry into the organization of knowledge workers in large numbers, and coping with increasing uncertainty in a global market (Jones \& Hendry, 1992; Mohrman, et al., 1989; Senge, 1990; Watkins \& Marsick, 1993; Kenny, 2006; Mayo, 2007). According to Khadra \& Rawabdeh (2006) review of the literature indicates that there is a significant positive relationship between learning organization practices and the performance of an organization. Top management team attraction was positively associated with superior returns (Michalisin, et al., 2006; Heath \& Brown, 2007). Unless organisations continuously develop their capacity and capability to learn, they are doomed to suffer from such adverse tendencies as market myopia, groupthink, reinventing the wheel and repeating the same mistakes (DiBella and Nevis,1998; Skerlavaj \& Dimövski, 2006).

It would appear as if it could be argued that an organisation's ability to learn faster than its competitors may be in future the only sustainable competitive advantage (De Geus, 1988; Donegan, 1990; Schein, 1993; Senge, 1990; Walker, 1992; Kenny, 2006; Jashapara, 2003; Skerlavaj \& Dimövski, 2006; Lim, et al., 2006; Michalisin, et al., 2006). Unless they can become learning organisations, they will not survive to do business in this millennium ( Senge, 1990). What, how, when, how smart and how fast an organisation learns has everything to do with its ability to compete.

Discussing how to define a learning organization precisely, Swieringa \& Wierdsma (1992:72) concluded: "We do not know what learning organisations precisely look like". Some attempts have, however, been made to define the characteristics and nature of such an organisation (Banner, 1987; Gharajedaghi \& Ackoff, 1984; Senge, 1990; Garratt, 1987; Senge, 1990; Garratt, 1987; Kochan \& Useem, 1992; Pedler, et al., 1991). Watkins \& Marsick (1993:8) seem to incorporate most of the elements of the definitions into their statement: "The learning organisation is one that learns continuously and transforms itself. Learning takes place in individuals, teams, the organisation, and even the communities with which the organisation interacts. Learning is a continuous, strategically used process integrated with, and running parallel to work. Learning results in changes in knowledge, beliefs and behaviors. Learning also enhances organisational capacity for innovation and growth. The learning organisation has embedded systems to capture and share learning".Yeo (2005) found in his research that a synthesis of the literature reveals several common themes stemming from various definitions of a learning organisation. He clearly differentiates between the term "organizational learning" to refer to the process of learning, and "learning organisation", which refers to a type of organisation rather than a process (Yeo,2003). Gorelick (2005) concluded that organisational learning and the learning organisation can and should co-exist (Skerlavaj \& Dimövski, 2006). Khadra \& Rawabdeh (2006) found in their study that learning and development is the only significant predictor of learning organizations.

The literature today is inundated by authors presenting the learning organisation approach as the new challenge for managers in an increasingly turbulent global business environment. The question remains, is the learning approach an effective and practical way for providing guidance to organisations not only now, but also into the future? The learning organisation approach to management has generated considerable interest in recent years among both scholars and practitioners. In fact, Nevis, DiBella \& Gould (1995) conclude from their studies on organisations, that all organisations are learning systems. But according to them learning conforms to culture, style varies between learning systems and generic processes facilitate learning (Nevis, et al, 1995:75). Dibella and Nevis (1998) argued that it is "a matter of perspective". They clustered the orientations of selected authors into three perspectives namely: 1) The normative perspective - organisational learning takes place under a unique set of conditions, relating to a specific type of organisation with specific characteristics (The Learning Organisation: A 
Matter of Becoming); 2) The developmental perspective - the learning organisation represents a late stage of organisational development; 3 ) The capability perspective - learning is innate to all organizations (The Learning Organization: A Matter of Being). They subsequently compare features such as time orientation, source, learning style, relationship between learning and culture, and management's focal point in order to indicate the differences between the three perspectives (DiBella and Nevis, 1998, p7-18). DiBella (2001) also developed the so-called “Organizational Learning Inventory” tool, used to profile a team's or organisation's learning capability.

When we undertake research, we seek to know "what is" in order to understand, explain, and predict phenomena. When dealing with a question like, "what is a learning organization?", concepts, constructs and definitions are required (Emory \& Cooper, 1991). Scientific methods and thinking are based on concepts that is, bundles of meanings or characteristics associated with certain events, objects, conditions, or situations. Concepts in turn are created by classifying and categorizing objects or events that possess common characteristics beyond the single observation. In research we often run into difficulty with concepts that have been newly advanced. Abstract concepts are termed constructs. A construct is an invented name for a property (Kerlinger, 1986; Anastase, 1986). Concepts and constructs must be defined operationally in order to measure the properties of a construct which is done by specifying the indicants of the properties (Emory \& Cooper, 1991; Kerlinger, 1986), a procedure discussed further below.

According to Kerlinger, "Measurement is the assignment of numerals to objects or events according to rules" (1986:392). Evidently measurement is a relation, a relation is a function and therefore all measurement procedures are functions (Kerlinger, 1986). It is said that the measurement procedure and the number system are isomorphic to reality, in other words that they possess identity or similarity of form. In measurement the question is: Do the measurement procedures being used have some natural and empirical correspondence with reality? Or, are the sets of objects the same or similar in some formal aspect? Obviously the ultimate question to be asked of any measurement procedure is therefore: Is the measurement procedure isomorphic to reality? Kerlinger (1986) has pointed out that we actually measure indicants of the characteristics of objects, where "indicant" signifies something that points to something else. So any identifiable behaviour of an organisation is an indicant of an underlying characteristic.

To the extent that measurement is reliable and valid, to that extent one will have faith in using its results consistently and with confidence in practice. Hence this paper reports on the discriminate validity of the "eleven characteristics questionnaire" of Pedler, et al. (1991). Reliability concerns the stability and accuracy of the instrument, while validity relates to what is being measured; are we measuring what we think we are measuring? Three types of validity are identified: content, criterion-related, and construct. Content validity considers the representativeness, or sampling adequacy of the content, criterion-related validity deals more with the predictive ability of the instrument, while with construct validity we wish to know the meaning of the test. We seek to explain individual differences in test scores. In other words, the properties being measured are more important than the test used for measuring. A significant feature of construct validity is its preoccupation with theoretical constructs and scientific empirical inquiry involving the testing of hypothesized relations. In the last case, convergence and discriminability are required, the former meaning that evidence from different sources gathered in different ways all points to the same meaning for the construct, while discriminability means that one can empirically differentiate amongst constructs that may be similar (Kerlinger, 1986; Anastasi, 1986).

Anastasie (1986) postulates that the development of a valid test requires multiple procedures which are sequentially built into the test from the outset of its construction. She (1986:12) summarized these processes very elegantly: "So-called content validation and criterion related validation can be more appropriately regarded as stages in the construct validation of all tests. There is a growing recognition that validation extends across the entire test construction process; it encompasses multiple procedures employed sequentially through internal and external statistical analyses of empirical data. Depending upon the purpose of the test, trait constructs may be defined with different degrees of narrowness or breadth and may be linked to specified situational domains. The identification of constructs in both test performance and criterion behavior increases the efficiency of the test construction process and leads to the production of tests that are more valid theoretically, as well as more useful in meeting practical needs". Almost any information gathered in the process of developing or using a test is therefore relevant to its 
validity, in the sense that it contributes to our understanding of what the test measures. Construct validation is indeed a never-ending process.

\section{RESEARCH METHODOLOGY}

\section{Participating Organisations}

The largest group of respondents in the present study stemmed from 30 different organizations which were functioning in various economic sectors and sub-sectors, viz. Agriculture ( 3 organisations: 48 respondents); Mining (3:35); Manufacturing (4:81); Electricity and Gas (2:63); Construction (2:22); Wholesale and Retail (5:44); Transport, Storage, Communication (3:56); Financial and Insurance (3:62); Community and Social Services (4:81). A second grouping of respondents comprised individuals who voluntarily completed the questionnaire while attending a Management Development Program ( $\mathrm{N}=124)$, Marketing Management Course $(\mathrm{N}=22)$ and a Logistics Management short course $(\mathrm{N}=19)$ at the Graduate School of Management of the University of Pretoria. In contrast with all the other respondents, the 124 students on the MDP had been exposed to some 2 hours o lectures on the theory of the learning organisation. In total 657 usable questionnaires were obtained.

\section{Measuring Instrument}

The questionnaire which was used had been developed by Pedler, et al. (1991). It consists of 110 items which are arranged under 11 scales i.e. the characteristics which are supposed to typify the learning organisation. Respondents were asked to react on a seven point scale, where $1=$ "not at all like this" and $7=$ "a lot like this". According to the given authors, the 11 characteristics can be grouped into five clusters. The structure of the variables which the instrument is supposed to measure is shown in Figure 1.

\section{Procedure}

Contact persons (agents) were arranged in each of the 30 organisations from which respondents were to be drawn. Questionnaires were given to the agents for distribution in the organisations of which they were members. The number of questionnaires handed to each agent was roughly proportional to the number of employees in the organisation. The agents were asked to distribute these questionnaires to potential respondents in proportion to the distribution of employees in the organisation in terms of hierarchical levels, functional groups, sex, age, home language and racial groupings. Agents were also asked not to distribute the questionnaire to the lowest level of employees or to top managers in their organisations. A deadline of one month after the distribution of the questionnaires was specified as the return date. Emphasis was placed on the voluntary completion of the questionnaires. The questionnaires were also personally handed to another 205 individuals attending short courses at the Graduate School of Management. The overall return rate of all questionnaires was $66.1 \%$. Of questionnaires distributed through agents in organizations $62.4 \%$ were returned and usable. The corresponding figure for questionnaires distributed to participants in short courses was $80.4 \%$. In total 657 questionnaires could be used in the analysis. Principal Components Analysis, utilizing the Statistical Analysis System on the computer system of the University of Pretoria, followed by Item Analysis were used to determine the underlying dimensions of the variables measured by The Eleven Characteristics of the Learning Organisation Questionnaire. 
Figure 1: Structure Of The Eleven Characteristics Questionnaire

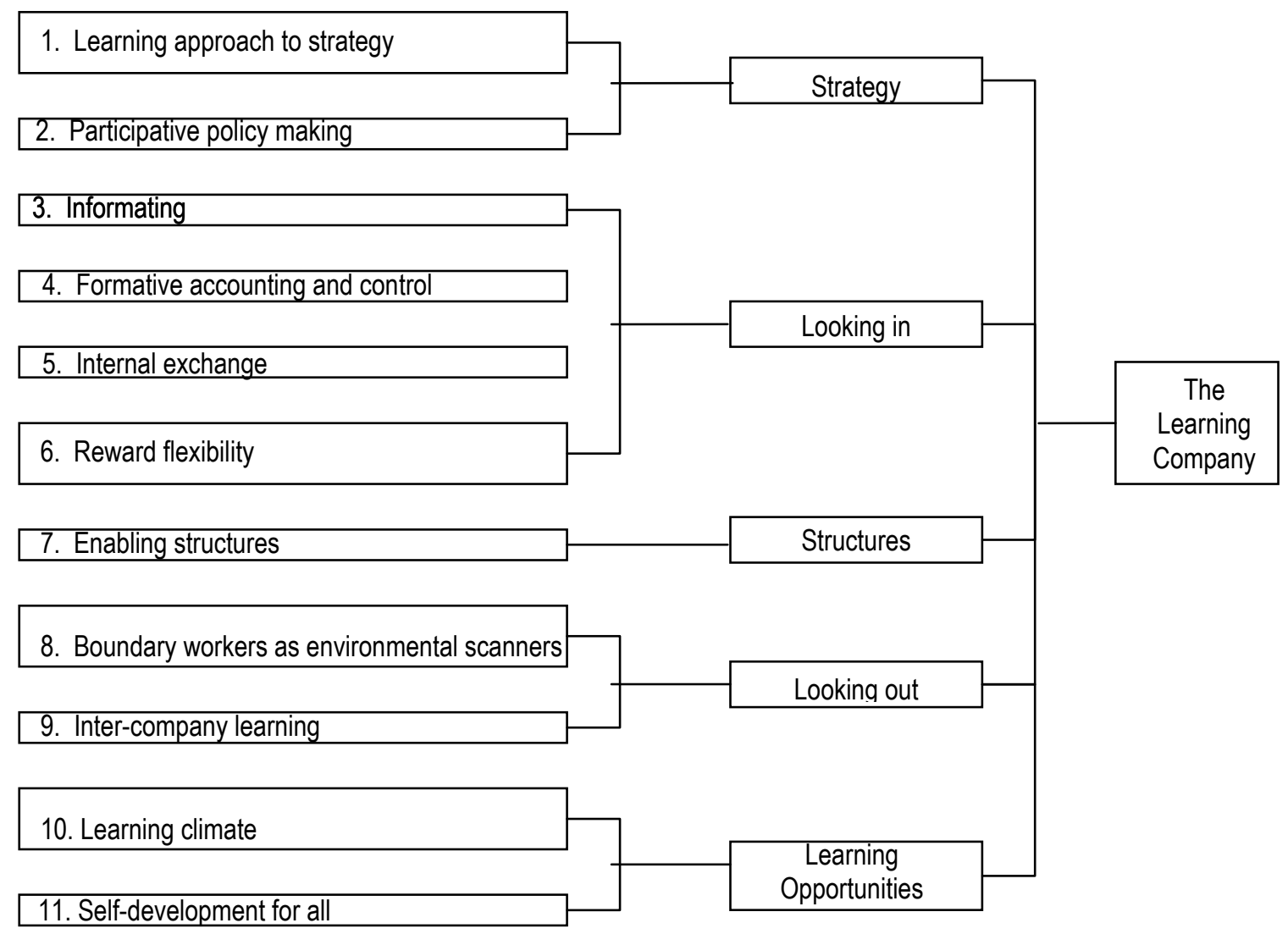

Source: Pedler, et al., $1991: 25$

\section{FINDINGS}

The purpose of the data analysis was firstly to determine the homogeneity of the items in the questionnaire as well as the underlying dimension(s) measured by the instrument. An attempt was therefore made to determine whether the "original" factor structure as defined by Pedler, et al. (1991) would be replicated by the findings of the responses gathered during the present study.

The first step of the analysis was to carry out a Principal Components factor analysis on the responses of the subjects. A Scree test was included to help with the interpretation. The "How it is" responses were used for this purpose. Varimax and Promax rotations were carried out. A total of 21 eigenvalues higher than one were obtained, the highest eigenvalue being 39.99 and the second highest 3.11. This large "distance" between the two highest eigenvalues created a suspicion that the items would possibly group into one underlying dimension. An 11-factor solution was, however, tried in order to see whether the structure as formulated by Pedler, et al. (1991) could be replicated. A Varimax rotation rendered 11 factors with the highest loadings on factors one to 11 being shown in Table 1. All the highest loadings were above .30. These 11 factors together explained $49.25 \%$ of the total variance. They respectively (rounded off) explained between 28.9 and $2.9 \%$ of the common variance (see Table 1) and between 31.8 and $1.2 \%$ of the total variance. The relatively small proportions of variance explained by the last ten factors seemed to point to a lower number of factors as being an optimum solution. There were also a large number of items which loaded on more than one factor. The large percentage of the total variance explained by the first factor $(31.8 \%$ ) against the $2.9 \%$ explained by the second factor seemed to point to the probability that the construct is measured by the instrument used in this study was possibly uni-dimensional. Since it was regarded as possible 
that the dimensions measured by the instrument would not be independent from each other a Promax rotation was also carried out again, extracting 11 factors. This yielded a factor pattern in which between 46 and 1 items loaded respectively on the 11 factors. The pattern of factor loadings was nearly the same as after Varimax rotation. The 11 factors now explained between 52.9 and $2.8 \%$ of the common variance (see also Table 1).

Table 1

Loadings On Factors In Varimax And Promax Rotations With \% Explanation Of Common Variance

\begin{tabular}{|c|c|c|c|c|}
\hline \multicolumn{2}{|c|}{ Varimax rotation } & \multicolumn{2}{c|}{ Promax rotation } \\
\hline Factors & Number of items & $\begin{array}{c}\text { \% Common } \\
\text { variance }\end{array}$ & Number of items & \% Common variance \\
\hline 1 & 45 & 28.9 & 46 & 52,9 \\
\hline 2 & 17 & 25.5 & 18 & 38,2 \\
\hline 3 & 11 & 10.5 & 11 & 27,9 \\
\hline 4 & 10 & 8.6 & 8 & 30,9 \\
\hline 5 & 9 & 8.4 & 5 & 18,3 \\
\hline 6 & 6 & 6.8 & 4 & 13,0 \\
\hline 7 & 5 & 5.8 & $2 *$ & 19,9 \\
\hline 8 & $2 *$ & 5.1 & $1 *$ & 3,9 \\
\hline 9 & 3 & 4.3 & $1 *$ & 3,7 \\
\hline 10 & $1 *$ & 3.3 & 2.9 & 2,8 \\
\hline 11 & $1 *$ & \multicolumn{3}{l}{} \\
\hline
\end{tabular}

Neither of the two 11-factor solutions (with Varimax or Promax rotations) replicated the 11-factor structure as proposed by Pedler, et al. (1991). The item loading pattern over the eleven factors as identified in this analysis bore no resemblance to the item distribution as identified by Pedler, et al. (1991). It was, however, decided to attempt a second line of analysis, i.e. item analysis to ascertain whether the items in the questionnaire were sufficiently related to each other to be regarded as contributing to the same scale. The corrected $r_{t t}$-values of the items varied between .34 and .73. As all items had $\mathrm{r}_{\mathrm{tt}}$-values of $>.30$, it was concluded that no items should be eliminated from the analyses and that all the items could be regarded as part of the same variable/scale.

A third line of analysis was to extract only one factor - partly promoted by the results of the item analysis which indicated that all the items correlated sufficiently to be regarded as part of one scale. This yielded a factor on which all the items loaded, the lowest being .34 and the highest .74. This result also pointed to the construct being uni-dimensional.

To learn more about the construct a second order factor analysis (using Principal Components) was carried out. The scores on the 11 factors were used as items. A Promax rotation was specified. A one-factor as well as a two-factor solution was specified. This analysis yielded one eigenvalue larger than one, i.e. 6.37 (The second highest eigenvalue was .83). The one-factor solution yielded a factor pattern in which all of the 11 original factors loaded above .30 (the lowest being .51and the highest .93). This one factor explained $61.2 \%$ of the total variance. The two-factor solution yielded two factors which had very high cross loadings. Only one of the original factors did not have its highest loading on the first of the two second order factors and only one of the original factors did not load above .30 on both factors. The two factors explained $68.8 \%$ of the total variance and 66.7 and $33.3 \%$ respectively of the common variance.

A final step of analysis, was that of applying Confirmatory Factor Analysis to determine which of the two solutions provided the best fit. The results are illustrated in Table 2. It seems that on most of the indices used, the one-factor solution provided a better fit and this solution was therefore accepted. Furthermore it appears as if it can be said, with confidence, that in the light of the evidence provided, the construct measured by the Pedler, et al. (1991) questionnaire is uni-dimensional. 
Table 2

Results Of C.F.A. On One- And Two-Factor Second Order Explanatory Analysis Results

\begin{tabular}{|c|c|c|}
\hline & One factor & Two factors \\
\hline Goodness of Fit Index (GFI) & .9587 & .9587 \\
\hline GFI Adjusted for df & .9366 & .9351 \\
\hline Root Mean Square Residual & .0253 & .0253 \\
\hline Parsimonious GFI & .7495 & .9873 \\
\hline Bentler's Comparative Fit Index & .9815 & 59.61 \\
\hline Akaike's Information Criterion & 57.61 & .9256 \\
\hline Mc Donald's Centrality & .9263 & .9756 \\
\hline Bentler \& Bonnett's Non-normed Index & .9764 & .9739 \\
\hline Bentler \& Bennett's NFI & .9739 & .7437 \\
\hline Parsimonious NFI & .7614 & .9659 \\
\hline Bollen Normed Index & .9667 & .9814 \\
\hline
\end{tabular}

It was demonstrated that the construct as measured in the Pedlar et al. (1991) questionnaire was unidimensional, and that the 110 items in the questionnaire were strongly related to each other, i.e. the measurement had high internal validity (Cronbach's Alpha $=.89$ ). However, some doubts exist about the content validity of the instrument and further work in this regard is recommended.

Utilizing the Statistical Analysis System on the main frame computer system of the University of Pretoria, investigation of the discriminatory/predictive ability of the instrument was carried out by means of One-way Analysis of Variance, Stepwise Discriminant Analysis and Discriminant Analysis. Items in the questionnaire which were identified by means of Stepwise Discriminant Analysis as contributing significantly to distinguishing groups from each other, were used in Discriminant Analysis to "place" individual respondents in groups. This was taken as a measure of the predictive/discriminatory validity of the instrument. The respondent groups were identified under "Method". The results of the One-way Analysis of Variance which were carried out are depicted in Table 3.

Table 3

Results Of One-Way Analyses Of Variance On The Scores Of Different Respondent Groups

\begin{tabular}{|c|c|c|}
\hline Criterion & F(df) & p \\
\hline Economic sectors & $2.01(8 ; 483)$ & $.04 *$ \\
\hline Organisations & $2.76(29 ; 462)$ & $.0001 * *$ \\
\hline Training course & $6.15(2 ; 162)$ & $.003 * *$ \\
\hline Exposure to concept & $2.93(1 ; 128)$ & $.09 * *$ \\
\hline
\end{tabular}

Significance at $5 \%$ level of significance

** Significance at $1 \%$ level of significance

Tukey's range test was in each case performed in order to pinpoint differences among groups more accurately. The results indicated that pair-wise comparison of groups' responses yielded significant differences, as illustrated in Table 4.

Table 4

Significant Differences Yielded By Tukey's Ranges Tests On Group's Scores

\begin{tabular}{|c|c|}
\hline Criterion & Differences and direction \\
\hline Economic sectors & $9>4$ \\
\hline Organisations & $16>26,5,8,17,11,20,21,19,14$, \\
& $29>11$ \\
& $30>11$ \\
\hline Training courses & Management Development> \\
& Marketing Management \\
\hline
\end{tabular}


The results of the Stepwise Discriminant Analyses can be summarized as in Table 5.

Table 5

Items Included In Stepdisc Models And Prediction Indices

\begin{tabular}{|c|c|c|c|}
\hline Criterion & Items* & Lambda & Canonical Correlation $^{2}$ \\
\hline Economic sector & $\begin{array}{l}32,20,107,88,31,5,23,70,80,26,3,37,104,57,36,29, \\
94,93,47,3,8,108,63,85,8,56,105\end{array}$ & .26 & .15 \\
\hline Organisations & $\begin{array}{l}32,31,42,20,91,47,93,107,29,108,70,3,1,88,57,53, \\
43,105,94,102,75,56,9,41,7,4,58,40,24,34,38,68,80 \text {, } \\
51,37,36,76,74,87\end{array}$ & .007 & .15 \\
\hline Training course & $70,73,99,77,26,18,64$ & .65 & .19 \\
\hline \multirow[t]{2}{*}{$\begin{array}{c}\text { Exposure to } \\
\text { concept }\end{array}$} & $26,65,11,42,93,5$ & .66 & .34 \\
\hline & * In order of contribution to the model & & \\
\hline
\end{tabular}

The Discriminant Analyses, using the models developed by means of the Stepwise Discriminant Analyses, yielded the results in Table 6.

Table 6

Percentages Of Correct Classifications By Means Of Discriminant Models

\begin{tabular}{|c|l|c|}
\hline Criterion & \multicolumn{1}{|c|}{ Percentage "Correct" per Group } & Percentage "Correct" Total \\
\hline Economic & $1-47.9 ; 2-54.3 ; 3-54.3 ; 4-55.6 ; 5-50.0 ; 6-50.0 ;$ & 46.9 \\
sectors & $7-33.9 ; 8-53.2 ; 9-30.9$ & 56.8 \\
\hline Organisations & $* 1-73.3 ; 2-62.5 ; 3-48.0 ; 4-72.7 ; 5-70.0 ; 6-100.0 ; 7-55.0 ; 8-64.7 ; 9-$ & \\
& $73.3 ; 10-58.6 ; 11-50.0 ; 12-63.2 ; 13-73.3 ; 14-57.1 ; 15---; 16-80.0 ;$ & 64.8 \\
& $17-57.1 ; 18-75.0 ; 19-100.0 ; 20-81.8 ; 21-50.0 ; 22-55.0 ; 23-42.3 ;$ & 76.9 \\
& $24-73.9 ; 25-84.6 ; 26-47.8 ; 27-100.0 ; 28-43.5 ;$ & \\
\hline Training course & $1-65.3 ; 2-59.1 ; 3-68.4$ & \\
\hline Exposure to & $1-82.1 ; 2-73.0$ & \\
\hline concept & & \\
\hline
\end{tabular}

\section{CONCLUSION}

It seems as if the first research question posed in the introduction to this paper can be answered in quite a straightforward manner. The learning organisation construct as measured by the Pedler, et al. (1991) questionnaire seems to be uni-dimensional. It was not possible to replicate the view of the authors of the questionnaire that eleven underlying dimensions are measured and that these dimensions could be clustered into five groups. The results point to a one-factor solution being acceptable. The second question - regarding the portability of the construct as measured by the instrument - can also be answered in the light of the results of the factor analysis and the item analysis. All the items loaded .30 or higher on the one factor identified. All the items also had $\mathrm{r}_{\mathrm{tt}}$-values of .30 or higher. It therefore seems as if the construct, and the items used to measure it, should be regarded as entirely portable/applicable to at least the South African cultural and organisational environment. Studies in other cultural environments could well be undertaken in order to determine whether the results of this study can be generalized (Khadra \& Rawabdeh, 2006). 
While some doubts still exist about the content validity of the instrument it seems clear that the Pedler et al. (1991) questionnaire must be regarded as measuring a uni-dimensional construct. The instrument exhibits high internal consistency (reliability), as can be expected of a long scale.

The study indicated that the instrument probably possesses useful predictive/discriminatory ability. It could distinguish adequately between respondents from different economic sectors, working in different organisations, respondents with different levels of exposure to the construct, and in different fields of specialization or interest, e.g. marketing and general management.

Further confirmatory research is needed on the content validity of the instrument, i.e. does it measure the concept "learning organisation" to its full extent? and on the predictive ability of the instrument: e.g. can it predict (over the medium to long term) organisational effectiveness (Khadra \& Rawabdeh, 2006; Michalisin, et al., 2006; Heath \& Brown, 2007)? A possible future study could be carried out to determine the relationship, if any, between the effectiveness/success of managers (Luthans, 1988; Michalisin, et al., 2006) and the degree to which the organisation conforms to the learning organisation concept. The research question might therefore enquire: Do subordinates of effective managers see their (learning) organisation differently from subordinates of successful managers (Dymock \& McMarthy, 2006; Skerlavaj \& Dimövski, 2006; Lim, et al., 2006; Michalisin, et al., 2006)?

Another possible future study could aim to determine the relationship, if any, between an organisation's learning and its strategy, and how it conforms to the learning organisation concept (Kenny, 2006; Prewitt, 2003). The research question could therefore ask: Is learning the result of strategy, or strategy the result of learning in a learning organisation?

Finally, the concept of the learning organisation should be investigated further. Is the degree to which an organisation is willing and able to learn not merely an aspect of an organisation's culture, world view, or mental models (Mayo, 2007; Jamali, et al.2006; Armstrong \& Foley, 2003; Pool, 2000)? Are these so-called "characteristics of a learning organisation" not merely facilitating factors in a learning culture (Armstrong \& Foley, 2003; Prewitt, 2003; Dymock,\& McCarthy, 2006)? Is it not more important in future to focus on the creation and improvement of learning capacity and learning capabilities in organisations (Kenny, 2006; Prewitt, 2003; Lim, et al., 2006), than to try and create a different type of organisation....... learning organization?

\section{REFERENCES}

1. Armstrong, A. and Foley, P. (2003), Foundations for a Learning Organization: Organizational Learning Mechanisms. The Learning Organization, 10(2), pp74-82.

2. Anastasi, A. (1986), Evolving Concepts of Test Validation. Annual Review of Psychology, 37(1), p.1.

3. Bahlman, T. (1990), The Learning Organization in a Turbulent Environment. Human Systems Management, 9, pp.249-256.

4. Banner, D.K. (1987), Of Paradigm, Transformation and Organizational Effectiveness. Leadership and Organisational Development Journal, 8(2), pp.17-28.

5. Braham, B.J. (1996), Creating a Learning Organization, Kogan Page, London.

6. Buckler, B. (1996), A Learning Process Model to Achieve Continuous Improvement and Innovation. The Learning Organization, 3 (3), pp.31-39.

7. Burgoyne, J., Pedler, M. and Boydell, T. (1994), Towards the Learning Company. McGraw-Hill, London.

8. De Geus, A. (1988), Planning as Learning. Harvard Business Review, 66(2), March/April, pp.70-74.

9. DiBella, A.J. (2001), Learning Practices. Assessment and Action for Organizational Improvement. Prentice- Hall, New Jersey.

10. DiBella, A.J. and Nevis, E.C. (1998), How organizations Learn. An Integrated Strategy for Building Learning Capability. Jossey-Bass, San Francisco.

11. Donegan, J. (1990), The Learning Organization: Lessons from British Petroleum. European Management Journal, September, 8(3), pp.302-312.

12. Dymock, D. and McCarthy, C. (2006), Towards a Learning Organization? Employee Perceptions. The Learning Organization,13(5), pp.525-536. 
13. Emory, C.W. and Cooper, D.R. (1991), Business Research Methods. Fourth Edition. Irwin, Boston.

14. Garratt, B. (1987), The Learning Organization and the Need for Directors who Think. Gower, Worcester, Great Britain.

15. Garratt, B. (1999), The Learning Organization 15 Years On: Some Personal Reflections. The Learning Organization, 6(5), pp.202-206.

16. Garvin, D.A. (1993), Building a Learning Organization. Harvard Business Review, 71(4), July-August, pp.78-91.

17. Gharajedaghi, J. and Ackoff, R.L. (1984), Mechanisms, Organisms and Social Systems. Strategic Management Journal, 5, pp.289-300.

18. Gorelick, C. (2005), Organizational Learning vs the Learning Organization: A Conversation with a Practitioner. The Learning Organization, 12(4), 2005, pp.333-388.

19. Guns, B. (1996), The Faster Learning Organization: Gain and Sustain the Competitive Advantage, JosseyBass, San Francisco, CA.

20. Hall, J. (1990), Bureaupathic Management: New Crisis in Organizations? Human Resource Management, Yearbook.

21. Hawkins, P. (1991), The Spiritual Dimension of the Learning Organization. Management Education and Development, 22(3), pp.172-178.

22. Heath, R.S. and Brown, Jr., J. F. (2007), A Re-Examination of the Effect of Job-relevant Information on the Budgetary Participation. Job Performance Relation during an Age of Employee Empowerment. Journal of Applied Business Research, $1^{\text {st }}$ Quarter, 23(1), pp.111-124.

23. Jamali, D., Khoury,G. and Sahyoun, H. (2006), From Bureaucratic Organizations to Learning Organizations. The Learning Organization, 13(4), pp.337-352.

24. Jashapara, a. (2003), Cognition, Culture and Competition: an Empirical Test of the Learning Organisation. The learning Organisation, 10(1), pp.31-50.

25. Jones, A.M. and Hendry, C. (1992), The Learning Organization: A Review of Literature and Practice. The HRD Partnership, London.

26. Kantabutra, S. (2006), Leader and Follower Factors in Customer and Employee Satisfaction: It takes Two to Tango. Journal of Applied Business Research, $4^{\text {th }}$ Quarter, 22(4), pp.33-46.

27. Kast, F.E. and Rosenzweig, J.E. (1985), Organization and Management. A Systems and Contingency Approach. Fourth Ed., McGraw-Hill, Johannesburg.

28. Kay, R. and Bawden, R. (1996), Learning to be Systemic : Some Reflections from a Learning Organization. The Learning Organization, 3(5), p.18-25.

29. Kenny, J. (2006), Strategy and the Learning Organization: a Maturity Model for the Formation of Strategy. The Learning Organization, 13(4), pp.353-368.

30. Kerlinger, F.N. (1986), Foundations of Behavioral Research. Third Edition. Holt, Rinehart and Winston, New York.

31. Kochan, T.A. and Useem, M. (Ed). (1992), Transforming Organizations. Oxford University Press, Oxford.

32. Khadra, M,F. and Rawabdeh, I,A. (2006), Assessment of Development of the Learning Organization Concept in Jordanian Industry Companies. The Learning Organization, 13(5), pp.455-474.

33. Lim, L.L.K.; Laosirihongthong, T. and Chan, C.C.A. (2006), A Case Study of Learning in a Thai Manufacturing Organization. Journal of Applied Business Research, 2 ${ }^{\text {nd }}$ Quarter, 22(2), pp.49-60.

34. Liu, C. (2006), Constructing a Value-Based Service Development Model. Journal of Applied Business Research, $4^{\text {th }}$ Quarter, 22(4), pp.47-60.

35. Marquardt, M.J. and Kearsley, G. (1996), Building the Learning Organization: A Systems Approach to Quantum Improvement and Global Success. McGraw-Hill, New York, NY.

36. Marsick, V.J. and Watkins, K.E. (1999), Looking Again in the Learning Organization: A Tool that can Turn into a Weapon. The Learning Organization, 6(5), pp.207-11.

37. Marsick, V.J. and Watkins, K.E. (2003), Demonstrating the Value of an Organization's Learning Culture: the Dimensions of the Learning Organization Questionnaire. Advances in Developing Human Resources, 5(2), pp.132-151.

38. Mayo, A. (2007), What are the Characteristics of a True Learning Organization? Strategic HR Review, 6(2), January/February, p.4. 
39. Michalisin, M.D.; Karau, S.J. and Conrad, E. (2006), Top Management Team Attraction as a Strategic

Asset: A Longitudinal Simulation Test of the Resource Based View. Journal of Applied Business Research, $3^{\text {rd }}$ Quarter, 22(3), pp.109-122.

40. Mohrman, A.M. (Jr), Mohrman, S.A., Ledford, G.E. (Jr), Cummings, T.G., Lawler, E.E. III and Associates. (1989), Large Scale Organizational Change. Jossey-Bass Publishers, London.

41. Moilanen, R. (2001), Diagnostic Tools for Learning Organisations. The Learning Organisation, 8(1), pp.620.

42. Moilanen, R. (2005), Diagnosing and Measuring Learning Organisations. The Learning Organisation, 12(1)., pp.71-89.

43. Nevis, E.C., DiBella, A.J. and Gould, J.M. (1995), Understanding Organizations as Learning Systems. Sloan Management Review, 36(2), Winter, pp.73-85.

44. Pedler, M., Burgoyne, J. and Boydell, T. (1991), The Learning Company. A Strategy for Sustainable Development. Mc Graw-Hill, London.

45. Pool, S. (2000), The learning Organization : Motivating Employees by Integrating TQM Philosophy in a Supportive Organizational Culture. Leadership \& Organization Development Journal, 21(8), pp.373-378.

46. Prewitt, V. (2003), Leadership Development for Learning Organization. Leadership \& Organization Development Journal, 24(2), pp.58-61.

47. Revans, R.W. (1982), The Origin and Growth of Action Learning. Lund (Sweden): Studentlitteratur.

48. Robinson, B. (1994), Voluntary Bodies as Learning Organizations. The Learning Organization, 1(3), pp.10-15.

49. SAS Institute Inc. (1988), SAS/STAT User's Guide. Release 6.03 Edition. Cary, NC: SAS Institute Inc.

50. Schein, E.H.S. (1993), How can Organizations Learn Faster? The Challenge of Entering the Green Room. Sloan Management Review, 34(2), Winter, pp.85-92.

51. Senge, P.M. (1990), The Fifth Discipline. The Art and Practice of the Learning Organization. Doubleday, New York.

52. Skerlavaj, M. and Dimövski, V. (2006), Social Network Approach to Organizational Learning. Journal of Applied Business Research, $2^{\text {nd }}$ Quarter, 22(2), pp89-98.

53. Stata, R. (1989), Organizational Learning - The Key to Management Innovation. Sloan Management Review, 30(3), Spring, pp.63-74.

54. Stewart, D. (2001), Reinterpreting the Learning Organization. The Learning Organization, 8(4), pp.14152.

55. Swieringa, J. and Wierdsma, A. (1992), Becoming a Learning Organization. Beyond the Learning Curve. Addison-Wesley Publishing Co., Amsterdam.

56. Teare, R. and Dealtry, R. (1998), Building and Sustaining a Learning Organization. The Learning Organization, 5(1), pp.47-60.

57. Walker, R. (1992), Rank Xerox: Management Revolution. Long Range Planning, 25(1), pp.9-21.

58. Watkins, K.E. and Golembeiwski, R.T. (1995), Rethinking Organization Development for the Learning Organization. The International Journal of Organizational Analysis, (3) 1, January, pp.86-101.

59. Watkins, K.E. and Marsick, V.J. (1993), Sculpting the Learning Organization. Lessons in the Art and Science of Systematic Change. Jossey-Bass Publishers, San Francisco.

60. Watkins, K.E. and Marsick, V.J. (1996), Creating the Learning Organisation. American Society for Training and Development, Alexandria, VA.

61. Yang, B., Watkins, K. E. and Marsick, V.J. (2004), The Construct of the Learning Organisation: Dimensions, Measurement and Validation. Human Resource Development Quarterly, 15(1), pp.31-55.

62. Yeo, R. (2003), Linking Organizational Learning to Organizational Performance: Singapore Case Studies. The Leadership and Organization Development Journal, 24(2), pp.70-83.

63. Yeo, R.K. (2005), Revisiting the Roots of Learning Organisation: a Synthesis of the Learning Organisation Literature. The Learning Organisation, 12(4), pp.386-382. http://www.efmd.org/html/home.asp (accessed March 2006). 